\title{
Anticancer Effect of Lycopene in Gastric Carcinogenesis
}

REVIEW

\author{
Mi Jung Kim, Hyeyoung Kim \\ Department of Food and Nutrition, Brain Korea 21 PLUS Project, College of Human Ecology, Yonsei University, Seoul, Korea
}

\begin{abstract}
Gastric cancer ranks as the most common cancer and the second leading cause of cancer-related death in the world. Risk factors of gastric carcinogenesis include oxidative stress, DNA damage, Helicobacter pylori infection, bad eating habits, and smoking. Since oxidative stress is related to DNA damage, smoking, and $H$. pylori infection, scavenging of reactive oxygen species may be beneficial for prevention of gastric carcinogenesis. Lycopene, one of the naturally occurring carotenoids, has unique structural and chemical features that contributes to a potent antioxidant activity. It shows a potential anticancer activity and reduces gastric cancer incidence. This review will summarize anticancer effect and mechanism of lycopene on gastric carcinogenesis based on the recent experimental and clinical studies.
\end{abstract}

(J Cancer Prev 2015;20:92-96)

Key Words: Anticancer effect, Lycopene, Gastric carcinogenesis

\section{INTRODUCTION}

Gastric cancer is one of the most common cancers in the world, following lung, breast and colorectal cancer. ${ }^{1.3}$ Risk factors of gastric cancer include poor diet, smoking, family history, inflammation, and Helicobacter pylori infection. ${ }^{4.5}$ Epidemiological studies have shown that diet including antioxidant nutrients plays an important role in prevention of cancer development. ${ }^{6,7}$ Especially, consumption of lycopene reduced risk of several cancers. ${ }^{8-10}$ However, compared to other cancers such as prostate cancer, anticancer effect of lycopene in gastric carcinogenesis has not been well studied. Lycopene is thought to be the active component in red fruits and vegetables such as tomatoes. In addition to its potential anticancer activity, lycopene supplementation decreased the occurrence of chronic diseases including type 2 diabetes, osteoporosis, and coronary heart disease. ${ }^{11}$ Since lycopene has 11 conjugated double bonds, it functions as the most potent antioxidant among carotenoids. ${ }^{12}$ Therefore, lycopene prevents the oxidative damage of DNA, lipids and proteins. ${ }^{13}$ Other potential mechanisms of lycopene include cell cycle arrest, modulation of immune function, and induction of apoptotic cell death. ${ }^{14}$ Lycopene also inhibited reactive oxygen species (ROS) production and decreased the phosphorylation of extracellular signal-regulated kinase (ERK), resulting in inhibition of cancer cell growth. ${ }^{6.15-17}$ Here, we review the anticancer effect and mechanism of lycopene in gastric carcinogenesis based on the recent advances in experimental and epidemiologic studies.

\section{ANTIOXIDANT ENZYME ACTIVITIES}

Oxidative stress-mediated DNA damage and tissue injury are related to cancer development. ${ }^{18,19}$ When the damaged cells divide, DNA duplication and cell metabolism become aberrant. Therefore, mutation is an important factor in carcinogenesis and oxidative damage could lead to carcinogenesis. ${ }^{20,21}$ Several studies reported that antioxidants inhibit oxidative damage and decrease abnormal cell division. ${ }^{22,23}$ Protective effect of antioxidants plays a critical role in prevention of cancer. Since gastrointestinal tract could easily be exposed to external and internal stimuli which produce ROS, the levels of antioxidants are especially important for preventing cellular damage. Antioxidants and

Received May 18, 2015, Revised June 20, 2015, Accepted June 20, 2015

Correspondence to: Hyeyoung Kim

Department of Food and Nutrition, Brain Korea 21 PLUS Project, College of Human Ecology, Yonsei University, 50 Yonsei-ro, Seodaemun-gu, Seoul 120-749, Korea Tel: +82-2-2123-3125, Fax: +82-2-364-5781, E-mail: kim626@yonsei.ac.kr, ORCID: Hyeyoung Kim, http://orcid.org/0000-0002-7019-917X

Copyright (c) 2015 Korean Society of Cancer Prevention

(c) This is an Open Access article distributed under the terms of the Creative Commons Attribution Non-Commercial License (http://creativecommons.org/icenses/by-nc/4.0) which permits unrestricted non-commercial use, distribution, and reproduction in any medium, provided the original work is properly cited. 
antioxidant enzymes including glutathione (GSH), glutathione peroxidase (GPX), glutathione-S-transferase (GST) are involved in scavenging oxygen free radicals. ${ }^{24}$ GSH protects essential cellular components from ROS-mediated damage and regulates cell proliferation. Lycopene, compared to other carotenoids and antioxidants such as $\alpha$-tocopherol and $\beta$-carotene, is a powerful antioxidant with a singlet oxygen quenching activity. ${ }^{25}$ Treatment of lycopene significantly reduced the extent of lipid peroxidation and enhanced the activities of GSH-dependent enzymes in gastric cancer rats. ${ }^{26}$ Lycopene reduced oxidative injury by stimulating levels and activities of GSH, GST, GPx enzymes in gastric cancer animals. ${ }^{27.28}$ These findings demonstrate that lycopene may have anticancer effect by increasing activities of antioxidant enzymes and reducing oxidative damage in gastric mucosa.

\section{CELL PROLIFERATION AND APOPTOSIS}

ERK signaling is involved in cell cycle checkpoints and mitosis. Therefore, ERK is considered as a major regulator of cell proliferation, apoptosis, and differentiation. ${ }^{29,30}$ Lycopene increased GO-G1 phase and decreased S phase in human gastric cancer HGC-27 cells. ${ }^{30}$ Lycopene inhibited phospholylation of ERK in gastric cancer cells as well as hepatocarcinoma cells. ${ }^{30,31}$ Yang et al. ${ }^{31}$ reported that enzymatic metabolite of lycopene, apo-8'-lycopena, suppressed protein expression of Rho small GTPases and inhibited focal adhesion kinase-mediated signaling pathway, such as ERK/p38 and phosphatidylinositol 3-kinase-Akt axis. These findings suggest that lycopene may contribute to antiproliferative effects in gastric cancer cells by inhibiting activation of ERK and inducing cell cycle arrest.

$\mathrm{Bcl}-2$ is considered as an important anti-apoptotic protein and regulates cell death. ${ }^{32} \mathrm{Bcl}-2$ inhibits apoptosis by reducing caspase activation such as caspase 3 and $8 .{ }^{33}$ Caspase 3, apoptosis-related cysteine peptidase, interacts with caspase 8 . These proteins are involved in the programmed cell death induced by various stimuli. $^{34}$ Apoptosis regulator Bax protein, a member of $\mathrm{BCl}-2$ family proteins, promotes apoptosis. As a pro-apoptotic protein, Bax induces release of cytochrome $\mathrm{C}$ and other pro-apoptotic factors from the mitochondria, leading to activation of caspases. ${ }^{35}$ Lycopene induced apoptosis in gastric cancer cells by decreasing Bcl-2 level and increasing the levels of Bax, caspase 3 and 8. 33.36

A tumor suppressor gene $\mathrm{p} 53$ regulates the balance of cell proliferation and apoptosis. Several studies reported that $\mathrm{p} 53$ is overexpressed in gastric cancer. ${ }^{37,38}$ In gastric mucosa of rats exposed to cigarette smoke, p53 is overexpressed. ${ }^{39}$ Upon p53 is activated, p53 target gene such as p21, a cyclin-dependent kinase inhibitor, regulates cell cycle arrest in G1 and induces apoptosis. ${ }^{40}$ Lycopene supplementation prevented changes in p53 expression in gastric mucosa of ferrets. ${ }^{39}$ Therefore, lycopene may protect against the development of gastric cancer by inhibiting p53dependent apoptosis and correcting the unbalance of apoptosis and cell proliferation.

\section{HELICOBACTER PYLORI}

Over half of the world's population is colonized with $H$. pylori which is a gram-negative bacterium. ${ }^{41} H$. pylori infection linked to chronic gastritis, gastric ulcers, and gastric cancer. One of the toxic factors in the pathogenesis of $H$. pylori infection is ROS.

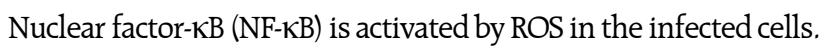
NF- $\kappa B$ activation leads to induction of TNF- $\alpha$ and chemokines in $H$. pylori-infected gastric epithelial cells. $H$. pylori-induced TNF- $\alpha$ and interleukin- 6 could alter gastric epithelial cell adhesion and result in migration of mutated epithelial cells. ${ }^{42}$ TNF- $\alpha$-inducing protein (Tip $\alpha$ ) binds to nucleolin which is localized on the surface of gastric cancer cells. ${ }^{43}$ Interaction between Tip $\alpha$ and nucleolin causes a cancer-oriented microenvironment that increases the risk of gastric cancer. $H$. pylori also induces activation of $\mathrm{ERK}^{44}$ which may be involved in hyper-proliferation of the infected cells.

H. pylori infection induced oxidative DNA damage. ${ }^{45,46}$ Jang et al. ${ }^{47}$ suggested that lycopene inhibited $H$. pylori-induced increases in ROS production and alterations in cell cycle distribution in gastric epithelial cells. In addition, $H$. pylori induced apoptosis with increased Bax and decreased Bcl-2 expression as well as cleavage of PARP-1. ${ }^{47}$ PARP-1, as an enzyme of DNA damage recovery, has a role in repair of single-stranded DNA breaks. These findings suggest that lycopene may be beneficial for treatment of $H$. pylori-associated gastric disorders even though clinical trial of lycopene as an adjunctive therapy for $H$. pylorieradication had no effect. $^{48}$

\section{EPIDEMIOLOGIC STUDIES}

As described above, in vitro and in vivo studies show anticancer effect of lycopene in gastric carcinogenesis. Many countries have implemented the clinical study of lycopene as the main component of tomato and tomato products An inverse association between tomato intake and gastric cancer incidence has been reported in some epidemiologic studies.

In China, meta-analysis study supports the negative relationship between tomato consumption and risk of gastric cancer. ${ }^{49}$ The risk of gastric cancer was significantly reduced in people 
consuming high lycopene compared to low intake group. ${ }^{49}$ High serum levels of lycopene were significantly associated with reduced risk of developing gastric cancer. ${ }^{50}$ In Finland cohort study, lycopene treatment did not affect the risk of gastric cardia cancer but decreased the risk of gastric noncardia cancer by $<33 \%{ }^{51}$ In a case-control study in Uruguay, tomato intake was strong inverse associations with stomach cancer development. ${ }^{52}$ In Japan, plasma levels of lycopene were lower in $H$. pyloripositive controls. ${ }^{53} \mathrm{H}$. pylori infection has been found to decrease the absorption of many nutrients. In the experiment by Ito et $\mathrm{al}^{54}$ serum levels of lycopene are associated with reduced risk of death from stomach cancer. They suggested that lycopene may be a promising biomarker to predict mortality from stomach cancer.

\section{CONCLUSION}

Lycopene from red fruits and vegetables has strong anticancer activity in gastric carcinogenesis. ROS have been implicated in the progression of several diseases including cancer. ROS cause severe cellular injury and promote tumor metastasis, angiogenesis, and invasion. As one of the most potent antioxidants, lycopene is effective in decreasing oxidative damage by activating antioxidant enzymes such as GSH, GPx and GST. Lycopene treatment inhibits cancer cell growth and induces apoptosis by suppressing ERK signaling pathway. Bcl-2 family and caspases are considered to be the most effective apoptotic regulators. Lycopene decreases Bcl-2 and increases Bax expression, which induce release of cytochrome C from mitochondria, leading to apoptosis. Lycopene treatment inhibits gastric cancer cell proliferation by increasing cell cycle arrest in G0-G1 phase. Moreover, lycopene prevents changes in p53 overexpression in gastric mucosa exposed to cigarette smoke. $H$. pylori infection is a high risk of gastric cancer. Lycopene inhibits $H$. pylori-induced increases in ROS levels and DNA damage in gastric epithelial cells. Korea is a high $H$. pylori prevalence and high gastric cancer incidence country. Since $H$. pylori infection rate in children is higher in Korea than other countries, consumption of red fruits and vegetables is recommended especially to the children to prevent $H$. pylori-associated gastric carcinogenesis.

Based on the studies, we propose a mechanism by which lycopene exerts protective effect against oxidative stress-mediated gastric carcinogenesis (Fig. 1). Smoking, inflammation, and H. pylori infection induce oxidative stress which leads to DNA damage, ERK activation and 533 overexpression, decreased activities of

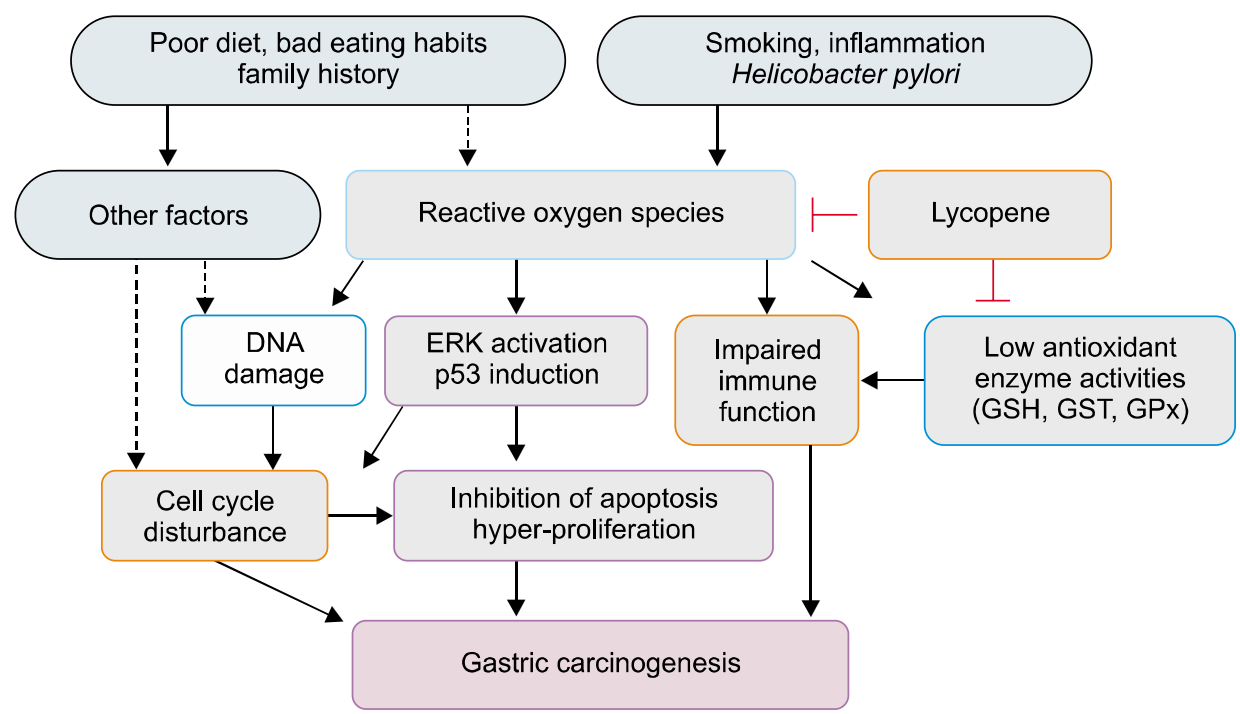

Figure 1. A schematic overview of the protective effect of lycopene against gastric carcinogenesis. Smoking, inflammation, and Helicobacter pylori infection induce oxidative stress which leads to DNA damage, ERK activation and p53 overexpression, decreased activities of antioxidant enzymes (GSH, GST, GPx) as well as impaired immune function. Low activities of antioxidant enzymes may decrease immune function of gastric mucosa. ERK activation and p53 overexpression induce cell cycle disturbances and inhibition of apoptosis as well as hyper-proliferation, resulting in gastric carcinogenesis. Poor diet, bad eating habits, and family history may be risk factors to induce DNA damage and cell cycle disturbances by affecting intrinsic factors or producing reactive oxygen species or oncogenic factors. Lycopene scavenges reactive oxygen species and stimulates activities of antioxidant enzymes, which protects gastric mucosa against oxidative stress-induced ERK activation, p53 induction, cell cycle disturbances, and impaired immune function. Therefore, lycopene may prevent oxidative stress-mediated gastric carcinogenesis. ERK, extracellular signal-regulated kinase; GSH, glutathione; GST, glutathione-S-transferase; GPx, glutathione peroxidase. 
antioxidant enzymes (GSH, GST, GPx) as well as impaired immune function. Low activities of antioxidant enzymes may decrease immune function of gastric mucosa. ERK activation and p53 overexpression induce cell cycle disturbances and inhibition of apoptosis as well as hyper-proliferation, resulting in gastric carcinogenesis. Poor diet, bad eating habits, and family history may be risk factors to induce DNA damage and cell cycle disturbances by affecting intrinsic factors or producing ROS or oncogenic factors. Lycopene scavenges ROS and stimulates activities of antioxidant enzymes, which protects gastric mucosa against oxidative stress-induced ERK activation, p53 induction, cell cycle disturbances, and impaired immune function. Therefore, supplementation of lycopene or consumption of lycopenecontaining fruits and vegetables may prevent oxidative stressmediated gastric carcinogenesis.

\section{ACKNOWLEDGMENTS}

This study was supported by a grant from the NRF of Korea, funded by the Korean government (MSIP) (NRF-2012R1A1A2043423).

\section{CONFLICTS OF INTEREST}

No potential conflicts of interest were disclosed.

\section{REFERENCES}

1. Persson C, Sasazuki S, Inoue M, Kurahashi N, Iwasaki M, Miura T, et al; JPHC Study Group. Plasma levels of carotenoids, retinol and tocopherol and the risk of gastric cancer in Japan: a nested case-control study. Carcinogenesis 2008:29:1042-8.

2. Tsugane S, Sasazuki S. Diet and the risk of gastric cancer: review of epidemiological evidence. Gastric Cancer 2007;10:75-83.

3. Crew KD, Neugut AI. Epidemiology of gastric cancer. World J Gastroenterol 2006;12:354-62.

4. González CA, Pera G, Agudo A, Palli D, Krogh V, Vineis P, et al. Smoking and the risk of gastric cancer in the European prospective investigation into cancer and nutrition (EPIC). Int J Cancer 2003; 107:629-34.

5. Uemura N, Okamoto S, Yamamoto S, Matsumura N, Yamaguchi S, Yamakido M, et al. Helicobacter pylori infection and the development of gastric cancer. N Engl J Med 2001;345:784-9.

6. Palozza P, Colangelo M, Simone R, Catalano A, Boninsegna A, Lanza $P$, et al. Lycopene induces cell growth inhibition by altering mevalonate pathway and Ras signaling in cancer cell lines. Carcinogenesis 2010;31:1813-21.

7. Liu C, Russell RM. Nutrition and gastric cancer risk: an update. Nutr Rev 2008;66:237-49.

8. Friedman M, Levin CE, Lee SU, Kim HJ, Lee IS, Byun JO, et al. Tomatine-containing green tomato extracts inhibit growth of human breast, colon, liver, and stomach cancer cells. J Agric Food Chem 2009:57:5727-33.
9. Tang FY, Cho HJ, Pai MH, Chen YH. Concomitant supplementation of lycopene and eicosapentaenoic acid inhibits the proliferation of human colon cancer cells. J Nutr Biochem 2009;20:426-34.

10. Teodoro AJ, Oliveira FL, Martins NB, Maia Gde A, Martucci RB, Borojevic R. Effect of lycopene on cell viability and cell cycle progression in human cancer cell lines. Cancer Cell Int 2012;12:36.

11. Salman H, Bergman M, Djaldetti M, Bessler H. Lycopene affects proliferation and apoptosis of four malignant cell lines. Biomed Pharmacother 2007;61:366-9.

12. Stahl W, Sies H. Lycopene: a biologically important carotenoid for humans? Arch Biochem Biophys 1996;336:1-9.

13. Palozza P, Simone R, Catalano A, Boninsegna A, Böhm V, Fröhlich $\mathrm{K}$, et al. Lycopene prevents 7-ketocholesterol-induced oxidative stress, cell cycle arrest and apoptosis in human macrophages. J Nutr Biochem 2010;21:34-46.

14. Rao AV, Ray MR, Rao LG. Lycopene. Adv Food Nutr Res 2006;51: 99-164.

15. Agarwal S, Rao AV. Tomato lycopene and its role in human health and chronic diseases. CMAJ 2000;163:739-44.

16. Qu M, Zhou Z, Chen C, Li M, Pei L, Chu F, et al. Lycopene protects against trimethyltin-induced neurotoxicity in primary cultured rat hippocampal neurons by inhibiting the mitochondrial apoptotic pathway. Neurochem Int 2011:59:1095-103.

17. Rao LG, Mackinnon ES, Josse RG, Murray TM, Strauss A, Rao AV. Lycopene consumption decreases oxidative stress and bone resorption markers in postmenopausal women. Osteoporos Int 2007;18:109-15.

18. Li X, Fang P, Mai J, Choi ET, Wang H, Yang XF. Targeting mitochondrial reactive oxygen species as novel therapy for inflammatory diseases and cancers. J Hematol Oncol 2013;6:19.

19. Smith KS, Yadav VK, Pedersen BS, Shaknovich R, Geraci MW, Pollard KS, et al. Signatures of accelerated somatic evolution in gene promoters in multiple cancer types. Nucleic Acids Res 2015:43:5307-17.

20. Sena LA, Chandel NS. Physiological roles of mitochondrial reactive oxygen species. Mol Cell 2012;48:158-67.

21. Halliwell B. Oxidative stress and cancer: have we moved forward? Biochem J 2007:401:1-11.

22. Pashkow FJ. Oxidative stress and inflammation in heart disease: Do antioxidants have a role in treatment and/or prevention? Int J Inflam 2011:2011:514623.

23. Ames BN, Shigenaga MK, Gold LS. DNA lesions, inducible DNA repair, and cell division: three key factors in mutagenesis and carcinogenesis. Environ Health Perspect 1993;101 Suppl 5:35-44.

24. Banerjee BD, Seth V, Bhattacharya A, Pasha ST, Chakraborty AK. Biochemical effects of some pesticides on lipid peroxidation and free-radical scavengers. Toxicol Lett 1999;107:33-47.

25. Di Mascio P, Kaiser S, Sies H. Lycopene as the most efficient biological carotenoid singlet oxygen quencher. Arch Biochem Biophys 1989:274:532-8.

26. Velmurugan B, Bhuvaneswari V, Nagini S. Antiperoxidative effects of lycopene during N-methyl-N'-nitro-N-nitrosoguanidineinduced gastric carcinogenesis. Fitoterapia 2002;73:604-11.

27. Luo C, Wu XG. Lycopene enhances antioxidant enzyme activities and immunity function in N-methyl-N'-nitro-N-nitrosoguanidineenduced gastric cancer rats. Int J Mol Sci 2011;12:3340-51.

28. Velmurugan B, Bhuvaneswari V, Burra UK, Nagini S. Prevention of $\mathrm{N}$-methyl-N'-nitro-N-nitrosoguanidine and saturated sodium 
chloride-induced gastric carcinogenesis in Wistar rats by lycopene. Eur J Cancer Prev 2002;11:19-26.

29. Kohno M, Pouyssegur J. Targeting the ERK signaling pathway in cancer therapy. Ann Med 2006;38:200-11.

30. Zhang B, Gu Y. Low expression of ERK signaling pathway affecting proliferation, cell cycle arrest and apoptosis of human gastric HGC-27 cells line. Mol Biol Rep 2014:41:3659-69.

31. Yang CM, Hu TY, Hu ML. Antimetastatic effects and mechanisms of apo-8'-lycopenal, an enzymatic metabolite of lycopene, against human hepatocarcinoma SK-Hep-1 cells. Nutr Cancer 2012;64: 274-85.

32. Yang J, Liu X, Bhalla K, Kim CN, Ibrado AM, Cai J, et al. Prevention of apoptosis by Bcl-2: release of cytochrome $\mathrm{c}$ from mitochondria blocked. Science 1997;275:1129-32.

33. Velmurugan B, Mani A, Nagini S. Combination of S-allylcysteine and lycopene induces apoptosis by modulating Bcl-2, Bax, Bim and caspases during experimental gastric carcinogenesis. Eur J Cancer Prev 2005; 14:387-93.

34. Porter AG, Jänicke RU. Emerging roles of caspase-3 in apoptosis. Cell Death Differ 1999;6:99-104.

35. Jürgensmeier JM, Xie Z, Deveraux Q, Ellerby L, Bredesen D, Reed JC. Bax directly induces release of cytochrome c from isolated mitochondria. Proc Natl Acad Sci U S A 1998;95:4997-5002.

36. Khan N, Afaq F, Mukhtar H. Apoptosis by dietary factors: the suicide solution for delaying cancer growth. Carcinogenesis 2007:28:233-9.

37. Starzynska T, Bromley M, Ghosh A, Stern PL. Prognostic significance of p53 overexpression in gastric and colorectal carcinoma. Br J Cancer 1992;66:558-62.

38. Kakeji Y, Korenaga D, Tsujitani S, Baba H, Anai H, Maehara Y, et al. Gastric cancer with p53 overexpression has high potential for metastasising to lymph nodes. Br J Cancer 1993;67:589-93.

39. Liu C, Russell RM, Wang XD. Lycopene supplementation prevents smoke-induced changes in p53, p53 phosphorylation, cell proliferation, and apoptosis in the gastric mucosa of ferrets. J Nutr 2006;136:106-11.

40. Hastak K, Agarwal MK, Mukhtar H, Agarwal ML. Ablation of either p21 or Bax prevents p53-dependent apoptosis induced by green tea polyphenol epigallocatechin-3-gallate. FASEB J 2005;19: 789-91.

41. Parsonnet J. The incidence of Helicobacter pylori infection. Aliment Pharmacol Ther 1995;9 Suppl 2:45-51.

42. Pathak SK, Basu S, Bhattacharyya A, Pathak S, Banerjee A, Basu J, et al. TLR4-dependent NF-kappaB activation and mitogen- and stress-activated protein kinase 1-triggered phosphorylation events are central to Helicobacter pylori peptidyl prolyl cis-, trans-isomerase (HP0175)-mediated induction of IL-6 release from macrophages. J Immunol 2006;177:7950-8.

43. Suganuma M, Watanabe T, Yamaguchi K, Takahashi A, Fujiki $H$. Human gastric cancer development with TNF- $\alpha$-inducing protein secreted from Helicobacter pylori. Cancer Lett 2012;322:133-8.

44. Zhu Y, Chen M, Gong Y, Liu Z, Li A, Kang D, et al. Helicobacter pylori FKBP-type PPIase promotes gastric epithelial cell proliferation and anchorage-independent growth through activation of ERK-mediated mitogenic signaling pathway [published online ahead of print February 16, 2015]. FEMS Microbiol Lett. doi: 10.1093/femsle/fnv023.

45. Sanderson MJ, White KL, Drake IM, Schorah CJ. Vitamin E and carotenoids in gastric biopsies: the relation to plasma concentrations in patients with and without Helicobacter pylori gastritis. Am J Clin Nutr 1997;65:101-6.

46. Obst B, Wagner S, Sewing KF, Beil W. Helicobacter pylori causes DNA damage in gastric epithelial cells. Carcinogenesis 2000;21: 1111-5.

47. Jang SH, Lim JW, Morio T, Kim H. Lycopene inhibits Helicobacter pylori-induced ATM/ATR-dependent DNA damage response in gastric epithelial AGS cells. Free Radic Biol Med 2012;52:607-15.

48. Shidfar F, Agah S, Ekhlasi G, Salehpour A, Ghourchian S. Lycopene an adjunctive therapy for Helicobacter pylori eradication: a quasi-control trial. J Complement Integr Med 2012;9:Article 14. doi: 10.1015/1553-3840.1588.

49. Yang T, Yang X, Wang X, Wang Y, Song Z. The role of tomato products and lycopene in the prevention of gastric cancer: A meta-analysis of epidemiologic studies. Med Hypotheses 2013; 80:383-8.

50. Yuan JM, Ross RK, Gao YT, Qu YH, Chu XD, Yu MC. Prediagnostic levels of serum micronutrients in relation to risk of gastric cancer in Shanghai, China. Cancer Epidemiol Biomarkers Prev 2004:13:1772-80.

51. Nouraie M, Pietinen P, Kamangar F, Dawsey SM, Abnet CC, Albanes D, et al. Fruits, vegetables, and antioxidants and risk of gastric cancer among male smokers. Cancer Epidemiol Biomarkers Prev 2005; 14:2087-92.

52. De Stefani E, Boffetta P, Brennan P, Deneo-Pellegrini H, Carzoglio JC, Ronco A, et al. Dietary carotenoids and risk of gastric cancer: A case-control study in Uruguay. Eur J Cancer Prev 2000;9:329-34.

53. Persson C, Sasazuki S, Inoue M, Kurahashi N, Iwasaki M, Miura T, et al; JPHC Study Group. Plasma levels of carotenoids, retinol and tocopherol and the risk of gastric cancer in Japan: a nested case-control study. Carcinogenesis 2008;29:1042-8.

54. Ito Y, Kurata M, Hioki R, Suzuki K, Ochiai J, Aoki K. Cancer mortality and serum levels of carotenoids, retinol, and tocopherol: a population-based follow-up study of inhabitants of a rural area of Japan. Asian Pac J Cancer Prev 2005:6:10-5. 